\title{
Esophageal Squamous Cell Carcinoma Location Category
}

National Cancer Institute

\section{Source}

National Cancer Institute. Esophageal Squamous Cell Carcinoma Location Category. NCI

Thesaurus. Code C133391.

Location of esophageal squamous cell carcinoma is defined by the position of the epicenter of the tumor in the esophagus. Location plays a role in the stage grouping of esophageal squamous carcinomas. (from AJCC 8th Ed.) 